\title{
BALANÇO DA GESTÃO 2008-2010
}

Nestes dois anos de gestão acontecimentos nacionais e internacionais de ordem política e econômica marcaram o mundo, destaque para a posse de Barack Obama, primeiro negro na presidência dos EUA, crise econômica mundial, crescimento do potencial econômico dos países emergentes - Brasil, Rússia, Índia e China (BRIC) - e as enormes catástrofes ambientais cada dia mais constantes em todo o mundo. Estes fatos nos impõem grandes desafios e nos levam a acreditar que a Química pode auxiliar na construção de um mundo melhor. Neste cenário de acontecimentos que marcaram o mundo, podemos afirmar que a gestão da SBQ (2008-2010) pôs em prática o plano de trabalho delineado no início do nosso mandato. Com dinamismo, concluímos nosso trabalho com um rol de realizações que, adicionadas ao de gestões anteriores, ajudou a criar, hoje, uma SBQ mais forte e cientificamente madura. Temos consciência do papel desta Sociedade no cenário nacional e internacional e de sua responsabilidade para com as questões nacionais, destaque para os problemas socioeconômicos locais e o desenvolvimento sustentável tão sonhado.

Ao assumirmos a Diretoria, com apoio do Conselho Consultivo, propusemos a criação de uma agenda de trabalho bastante ampla e inovadora, visando inserir a SBQ nas grandes questões nacionais, a saber: participação nos principais fóruns de $P \& D$ e nas questões de desenvolvimento que dizem respeito à área da Química. O momento nacional nos levou a estabelecer um fórum constante de discussão e contato com representantes políticos, empresariais e civis. Destacamos algumas das ações relevantes e que certamente servirão de base para as ações da nova gestão, como o contato permanente com instituições governamentais e empresariais, que respaldaram a importância da SBQ nos fórum de política de ensino, pesquisa, desenvolvimento tecnológico e inovação. Como exemplo destes contatos estivemos presentes no encontro com o Presidente Lula na SBPC de 2009 para entrega de um documento da Sociedade sobre os marcos regulatórios atuais, dessintonizados da própria política de $\mathrm{P} \& \mathrm{D}$ traçada por este governo. Além disso, tivemos audiências com os Ministros de Ciência e Tecnologia Sérgio Rezende, da Educação e Cultura Fernando Haddad e do Meio Ambiente Carlos Minc para discutir o potencial da área de Química no plano de estado de ciência e tecnologia nacional de médio e longo prazos. A SBQ também propôs ações para minimizar os problemas que a lei de acesso à biodiversidade trouxe para a pesquisa básica e tecnológica, envolvendo ativos da nossa riqueza biológica. Com relação a este tópico, a tramitação das solicitações de licença para coletas pelo $\mathrm{CNPq}$ pode ser contabilizada, em parte, aos esforços de nossa Sociedade que, aliada à SBPC e às outras sociedades científicas, muito contribuiu para seu aprimoramento. Encontros com o Secretário Executivo do
MCT, José Antonio Elias durante duas reuniões do Fórum Consecti-Confap, com o ex-presidente do CNPq, Marco Antonio Zago e o atual, Carlos Alberto Aragão e com Gustavo Ribeiro, Diretor do Departamento de Normas e Competitividade de Comércio Exterior do MIDCE marcaram a presença da SBQ no governo e nas questões que dizem respeito à Química. Aproximar a SBQ de outros setores, incluindo o empresarial, foi outra tarefa bem sucedida, principalmente pela aproximação com ABIQUIM, Sindicato dos Químicos e Conselho Regional de Química de São Paulo (CRQ-IV).

A internacionalização da SBQ atingiu as expectativas esperadas desta gestão. Nestes dois anos estreitamos ainda mais os laços da SBQ com outras sociedades científicas internacionais como IUPAC, ACS, RSC, Sociedade Italiana de Química, Sociedade Mexicana de Química, Sociedade Colombiana de Química e a FLAQ, através da promoção de reuniões e simpósios conjuntos sobre temas atuais, como bioenergia, biodiversidade e ecossistemas, química verde, e sobre o Ano Internacional da Química - AIQ-2011 (International Year of Chemistry - IYC-2011), além de outras propostas de trabalho colaborativo futuro.

A Editoria da SBQ, com suas três publicações - JBCS, Química Nova e QNEsc - continuou sua trajetória de sucesso, completamente apoiada em suas reivindicações por esta gestão. Tivemos neste período a comemoração dos 20 anos de existência do $J B C S$, durante o $61^{\circ}$ Congresso da SBPC, ocorrido em Manaus, onde foi lançado um número especial sobre a Amazônia. Consciente da importância estratégica da nossa biodiversidade para a economia nacional, um número especial da Química Nova sobre Recursos Naturais foi editado - Oportunidades na Academia e na Indústria, com a participação de renomados cientistas e a colaboração editorial do Conselheiro Fernando Galembeck e da Editora da QN, Vera Pardini. Novidade alvissareira neste período foi a criação do QNInt, o portal de química interativa criado para atender professores e estudantes de ensino fundamental e médio. Um dos maiores gargalos para o desenvolvimento tecnológico do país hoje é a educação nos níveis fundamental e médio. A QNInt, criada nesta gestão sob a coordenação do Conselheiro Jailson B. de Andrade e essencial colaboração dos Profs. Guilherme A. Marson e Eduardo Galembeck, é ação que enobrece a Sociedade. A meta maior deste portal é a formação educacional, interativa, visando oferecer aos professores da rede pública e particular de ensino e aos jovens estudantes conteúdo didático e conhecimento com fonte certificada. Com isso almejamos contribuir efetivamente para minimizar o tremendo desequilíbrio que existe entre os ensinos de nível fundamental, médio e superior 
do país. Outra ação deste período voltada para a formação de jovens adolescentes, com conteúdo descontraído e lúdico, foi a criação da página web QuiD+, sob coordenação da, então, $1^{\text {a }}$ Secretária e atual Tesoureira Profa. Claudia Rezende. A EditSBQ, mesmo enfrentando as dificuldades inerentes à edição de livros, editou, sob a coordenação do Prof. Celso C. Moro, o livro "SIMÃO MATHIAS CEM ANOS Química e História da Química no início do século XXI”, cujo lançamento oficial ocorrerá em breve.

A modernização do parque de informática da SBQ, incluindo Secretaria Central, Secretarias Regionais, Divisões Científicas, cadastros de sócios e a nova edição do Boletim, completamente inovador, teve início nesta gestão. Quando concluída, trará uma série de benefícios para toda a comunidade. O novo sistema de informatização é suficientemente robusto para a SBQ enfrentar seu crescimento nos próximos 15 anos. Acreditando que uma sociedade forte e consolidada deve ter um canal de divulgação profissional, contratamos os serviços de um jornalista para que as ações da nossa sociedade tenham mais visibilidade extramuros.

A 33 a Reunião Anual da SBQ, em 2010, teve um caráter especial, pois marcou o início das comemorações no Brasil do AIQ-2011. A temática A Química construindo um futuro melhor teve como objetivo conclamar a comunidade da SBQ e todos que atuam nesta interface no Brasil a se juntarem aos nossos esforços para uma grande celebração, que tentará envolver a sociedade brasileira em uma análise profunda do real papel da Química no desenvolvimento de um futuro melhor. Assim, 2025 foi escolhido como ano base para esta projeção, tanto sob o ponto de vista de desenvolvimento científico e tecnológico quanto da formação do químico. Foi, também, uma oportunidade de apresentar aos associados os projetos e ações criados pela Diretoria e Conselho para serem aplicados em todo o território nacional em comemoração ao AIQ-2011. O sucesso da reunião pode ser medido em seus números: pelo segundo ano consecutivo batemos os recordes de participantes, com a presença de 2.710 inscritos, contra um número inicial de 3.170 pré-inscritos. Foi submetido um total de 2.820 trabalhos e 2.514 foram de fato apresentados. O número de atividades mostra a complexidade e diversidade das atuais RAs, com 14 conferências, 56 miniconferências e 72 apresentações orais. $\mathrm{O}$ enorme contigente de jovens estudantes e pesquisadores na $33^{\mathrm{a}}$ RASBQ foi o ponto marcante da reunião, tendo em conta o compromisso da SBQ na formação dos futuros cientistas da área no Brasil. Foi para estes jovens que preparamos a sessão "conversa com o Prêmio Nobel Martin Chalfie", uma micro "Lindau" para os nossos estudantes.
A ideia de construir um futuro melhor tem implicações de grande alcance e se traduz em preocupações diferentes daquelas que afetavam as gerações anteriores. Ciência e Tecnologia foram, durante muito tempo, ferramentas para o conhecimento da natureza, com a finalidade de satisfazer, a qualquer preço, as necessidades do homem. A Química, desde sua origem como ciência fundamental, exibe um perfil particular ao cumprir essa tarefa, pois seu domínio está estreitamente ligado à indústria e à produção de bens. Também está ligada a algumas das mais sofisticadas criações humanas no campo da Medicina e da Agricultura, que asseguram a sobrevivência de milhões de pessoas. No entanto, o "futuro melhor" que se vislumbra hoje requer mais que isso. Exige uma nova visão sobre Ciência e Tecnologia. Uma visão em que a sustentabilidade do meio ambiente e da qualidade de vida humana são partes integrantes de qualquer projeto tecnológico imbuído no desenvolvimento, seja nacional ou internacional. Na visão da gestão SBQ 2008-2010, uma das premissas para um futuro melhor é a interlocução com a sociedade e a efetivação de canais de comunicação que disseminem o conhecimento gerado pela universidade e pelos centros de pesquisa. Embora essa visão sempre tenha estado presente nas realizações da entidade, ela ganhou força na $33^{\mathrm{a}} \mathrm{RASBQ}$, com o início da celebração do AIQ-2011, e se estenderá até a próxima $34^{\mathrm{a}}$ RASBQ que acontecerá em maio de 2011, no Costão do Santinho, em Florianópolis. Como é de conhecimento de todos, a celebração do AIQ-2011 foi definida pela UNESCO e pela União Internacional de Química Pura e Aplicada, IUPAC, organizações responsáveis pela coordenação em âmbito mundial de uma série de atividades destinadas a valorizar e divulgar esse campo da ciência. Sob o lema Chemistry - our live, our future (Química - nossa vida, nosso futuro) serão realizadas iniciativas que têm entre os seus objetivos popularizar as grandes descobertas e os últimos avanços conquistados pela Química. É também um ano de celebração do papel das mulheres na ciência, como uma justa homenagem às conquistas femininas, já que nos dias atuais as mulheres vão ocupando espaços cada vez mais competitivos em todas as atividades e liderando com menos vaidade e mais sensibilidade, dando uma enorme contribuição para a construção de um mundo melhor, mais digno, justo e humano.

Vanderlan da Silva Bolzani

Presidente da SBQ 2008-2010

Luiz Henrique Catalani

Secretário Geral da SBQ 2008-2010 